\title{
PROSTHETIC SURFACE - DESIGN MODELS FOR A DYNAMIC ARCHITECTURE
}

\author{
DAGMAR REINHARDT \\ Reinhardt_Jung [architektur und ingenieurbüro] \\ Brückenstr 52, D- 60594 Frankfurt/ M, Germany \\ Reinhardt5@yahoo.com
}

\begin{abstract}
The research investigates strategies of dynamic surface formations in a transfer from sartorial fashion to architecture. 'Remote Control Dress' (Hussein Chalayan), 'Dress becomes Body (Rei Kawakubo) and 'A-Poc' (Issey Miyake) are precedents of specific technologies and techniques that produce responsive, performative, or phenomenal dresses. These garments can deliver generative surface methods for an architecture operated through the user. The research frames key parameters (cutting scheme, constructive line, programmatic insertions, and operative field) and their respective characteristics and interrelations in analysis. Thus, principles are derived and channeled into performative design models in a media rotation with a conversion between digital and analogue modeling. The paper discusses the potential of these dynamic design models in a design process that addresses the change capacities of architecture in a shifting cultural and programmatic context.
\end{abstract}

\section{Introduction}

What is the structure of change? What capacities are required of form in the shifting spatial parameters of a transitional environment? Architecture is a prosthetic device, and, similar to other cultural expressions like language, fashion or art, submissive to continuous transformation. A successful prosthesis is able to answer a number of change conditions, but also undergo a process of modification, differentiation - in short, a process of evolution. Prosthetics can be mapped according to 'technologies of the body' (Quinn 52) that range from restorative (replacing lost functions), over normalizing (imposing new social or aesthetic norms) to reconfiguring (changing the contextual relations) and enhancing (increasing functions or properties) aspects.

While most prosthesis are devices (objects), the paper researches the potential of prosthetic surfaces that register change conditions and react as a dynamic system. The mutual congruence of methods, techniques and effects in fashion and architecture surfaces is used to identify concepts for organization, structure and detailing of form alterations in a responsive, performative, interactive system. The different concepts of prosthetic surfaces are then applied to the architectural design process.

Sartorial fashion is rapid, ephemeral, experimental, thus a predestined medium of cultural phenomena. In fact, fashion is composed of change (Wilcox 6). In this context, shapes have 
increasingly emerged that show an alteration, variation or transformation in form and material. Works by Hussein Chalayan, Rei Kawakubo (Comme des Garcons) and Issey Miyake reflect change as adaptation to a user. They are a species different from generic functional tailoring; heralds of a territory in which the permanence of shape, form and program are challenged. Instead of styles and determined shapes, these fashion experiments reveal fields of elasticity, intensity and compression (Grosz 127), employ programmatic insertions and digital extensions, or are operated through mechanical gearing. Thus, substance and formation of these surfaces are latent, as changes emerge in phases and ranges, shifting from one programmatic and textural condition into another.

While illustrative and representational comparisons between effects and techniques of body, dress and architecture have been explicitly framed (Evans, Wilcox, Quinn), Hoodge further discusses parallel practices between fashion and architecture, from design and organization, to production techniques and form effects: 'Both fashion designers and architects begin by taking an idea, and, working out its practical requirements, translating it into a three-dimensional structure using flat materials' (Hoodge 17).

In addition, this paper suggests that fashion and architecture share a number of principles or concepts embodied in structure and material through which a surface formation can be made fit for change. Rather than using visual similiarities (produce an object that looks like it), or shared platforms (use the same software) the paper uses a cross-reference of shared methods in fashion and architecture for an identification of principles that produce a type of prosthetic surface (changing in basis, effects and phenomena).

The fashion examples discussed in the following establish different types of surface prosthesis. Each is based on a three-dimensional concept with inherent methods, materiality and production techniques. Once abstracted, a combination of these strategies and principles may deliver Design Models to be applied in the architectural design process. The Design Model is a generative engine that administers technique and transfer in different media and materials. The paper explores in which way a fashion reference might be transformed into a Design Model that produces an immediate, three-dimensional formation with material and structural facets, yet devoid scale and program. These Design Models might then enable multiple, specified, heterogeneous, differential conditions, and become strategies for a new spatial semiotic.

\section{Surfaces: Design Model and Parameters}

Architecture is already processed as a continuous formation that organizes spatial sequences through surface effects (Benjamin 5). Increasingly, software programs are used to develop and organize design projects through the deformation of surface under data impact (Lynn "Animate" 10). Infinitely variable while located in a digital realm, the transfer of zero-thickness objects into material, structure, depth, occupancy becomes an issue.

In contrast, the technique of fashion production is immediate in form definitions, material and structural explorations in the product milieu - on the body. Thus it can deliver an organizational paradigm to articulate architecture not as primarily engaged with form generations, but with a material or structural immediacy. Change conditions, a shift in functional profile can then be formatted as material and structural principle already in the design phase.

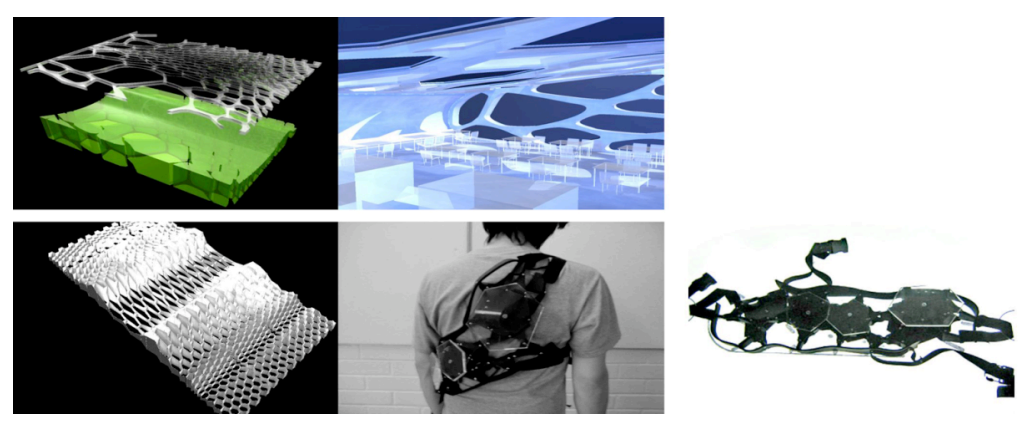

Figure 1: Design Model and Media Applications (Toshimune Suzuki, Elastic Space Studio, Sydney 2005-02) 
In answer to these requirements, the Design Model forms idea and concept, independent from site and programmatic demands. It contains 'packages of organizational or compositional principles' (Un Studio 18). The Design Model regulates (describe, administer, explore) fabric, detail, structural and aesthetic components. Its formative power derives from a capacity of perpetual transformation in response to process and data, through a multiple iterative conversion and exploration in analogue and digital media (Herbert 22).

The Design Model enhances project precision and aesthetics through coherence. The essence of an idea is maintained even if it evolves through different shapes, because framework and settings are constantly edited and adjusted. Once established, the Design Model can be employed on various levels, scales, and application. A Design Model can define strategies for body-formatted devices, or interior façade prototypes, to organizations of urban structures (Fig 1).

The works by Chalayan, Miyake and Kawakubo demonstrate concepts and principles that connect with a Design Model typology with dynamic, phenomenal, responsive, elastic conditions. Though all fashion examples exist in a range or phase conditions, they differ in operative modes. Each addresses change options in an individual manner, through specific characteristics in structural or material prototyping and detailing within their architectural section. The specificity of those concepts can be framed by number of selected parameters. Strategies for cutting scheme, constructive line, programmatic insertions, and operative field (Reinhardt) were applied and developed into a series of Design Models in the Elastic Space Studio and Prosthetic Surface Studio [Master of Architectural Design, Sydney University, 2005-06, research spatial constructs and surface formation for responsive, interactive environments].

Responding to the concept approach, these parameters interplay in the formation of a prosthetic surface. The cutting scheme is a strategic mapping device that organizes the sum of descriptive lines within an ambiguous surface. Aspects of potential shapes, forms and operations are changed, programmed and optimised until the moment of cut, when the form becomes definite. The constructive line is the control mechanism in construction or production, it is hem, seam, line of coalescence, where materials are joint. This line defines a contour of exterior shape and interiorized sub-sections, and becomes a major agent of change when repositioned. Both cutting scheme and constructive line describe concepts that originate in a fashion context, yet might be applied to architectural design. The programmatic insertions are alien volumes inserted after fabrication or predetermined densifications implemented in an ambiguous or prepared structural field. They are ephemeral electronic/digital extensions, programmatic pockets or independent occupational zones that produce a recoding of the surface field. The operative field shows the effect of surface conditioning and formation through techniques, changing the operative field, visible as structural or material contraction and expansion.

Sato describes the 'rethinking [of] received ideas and the modes of production' as a major path for the derivation of new creative solutions (Sato "Making" 23). The paper thus focuses on effect, mechanics and technology behind shapes and their operations, and the implications on methods of surface organization, techniques, structure and material detail applied to architecture.

\section{Fashion Works: Surface Transformations}

The 'Remote Control Dress' by Hussein Chalayan, 'Dress becomes Body' by Rei Kawakubo (Comme des Garcons) and 'A-Poc' by Issey Miyake are works chosen to demonstrate strategies for Design Models with a dynamic potential, applied to the architectural design process.

Though their effects vary, they depart from similar premises. None of them is based on a cutting scheme that resembles generic clothes. These shapes are oversized, deformed, idealized. Some are independent objects, statically self-sufficient, detached from the body contour, thus already mediate between dress and architecture. Their surfaces range from ambiguous to intense textural fields, they reveal a depth in operation through which they can responds to programmatic or sequential shifts. This depth is registered into the system as the structural coding of a mesh, the mechanical gearing of a shell, the conjunction with diverse textural layers or digital networks, or through temporal insertion of subvolumes.

Although these fashion explorations display strong figures, the form is not yet defined. A tendency towards unfinishedness, indeterminacy, and incompleteness is shared. These works request the wearer to finalize the product in a post-productional form definition. The ultimate forms needs to be cut from the fabric, electronic signals have to be given via remote control. 
They produce these effects as individual approaches, clearly legible concepts that are materialized, in this manifestation as dresses.

\subsection{Design Model 1: Programmed Mesh}

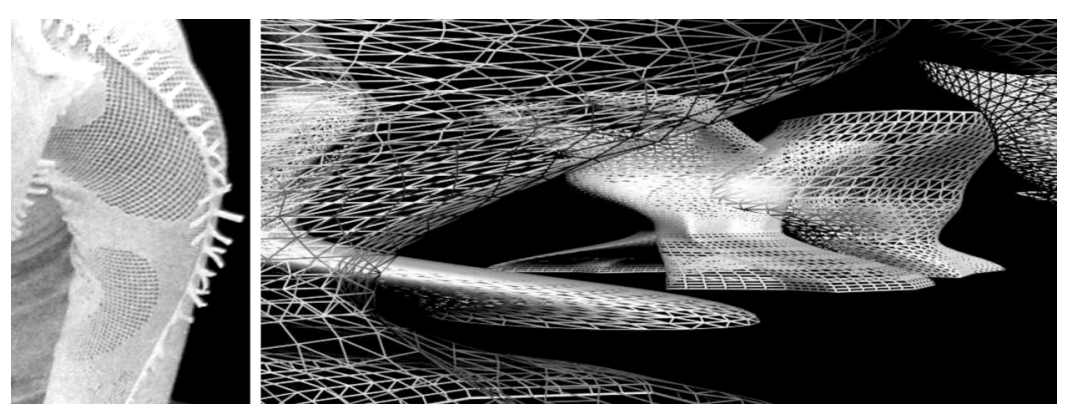

Figure 2: Mesh Configurations.

Left: Detail of Issey Miyake, 'A-POC' (Miyake, Issey and Fujiwara, Dai. A-POC Making. Weil Am Rhein: Vitra Design Museum, 2001)

Right: Renee Fu, Prosthetic Surface Studio, Sydney 2006-02

One Design Model for an intentionally delayed form definition process is a coded mesh configuration (Fig 2). 'A-POC' (Issey Miyake, 1998) uses such a principle of surface formation that displays diverse zones of compression and intensity, programmed through digital weaving techniques. Here, shapes, colours, applications a similar range and depth of variation as the former basic technique applied in the Miyake production explored ('Pleats Please')

Miake reverses traditional techniques of fabrication, instead, 'a thread goes into a machine that, in turn, generates complete clothing using the latest computer technology, eliminating the usual need for cutting and sewing the fabric.' (A-POC making: 68). A-POC is based on the raschel knit tube, a fabric volume of variable length executed in a one-and zero binary language that translates 'sink' and 'surface' machine signals into the movement of an automated weaving (Fujiwara 71). This technology is a continuation of a mass-production based on Jacquard's automatic loom technique combined with the pre-digital code of Hollerith's punch card indexes (McCarty and McQuaid 101).

In the mesh fabric, 'lines of demarcation create a pattern of surface design that in turn becomes structural seams' (De la Haye 34). Its respective zones differ in threat properties, luminosity, ornamentation, layering, densities and expandability. The mesh frames the blueprints of potential dresses. From a potential form and number of clothing items (dress, shirt or skirt, ect), one future item is selected and cut free (Kries 66, Quinn 150).

The structural code of the mesh gives an area in which the cut can be applied. It thus uses a delayed cutting scheme, in which the customer defines the ultimate shape. Quinn classifies these garments as 'shapeless designs' (153), yet these garments receive their shape in operation. The programmatic code inscribed in the mesh uses an elastic or expansive depth that results in an interval behavior (Hiramitsu). The interval frequency determines another potential adaptation; it mediates between production shape and body contour, and contour and highest pitch of movement, adding a micro-scale change option to the surface texture. The homogeneous character of this surface fabric abandons a determined constructive line, in favor of an operative field that reacts to change conditions in total.

This Design Model of a coded mesh configuration is characterized by a three-dimensional structural code, an interval range between diverse programmatic zones, and a sequential duration of various occupants. It is a 'ready-made, ready to be remade' (Simon). In the design process, it enables perpetual connections, size and scaling operations. Incorporated in a static shell, the design model may be used for a differentiation of programmatic zones, as an interior architecture device. This mesh definition is of course one amongst many. Other options may shift in purpose towards parametric deformation, or inserts stable fields between nodal points, etc. 


\subsection{Design Model 2: Remote Controlled Shell}

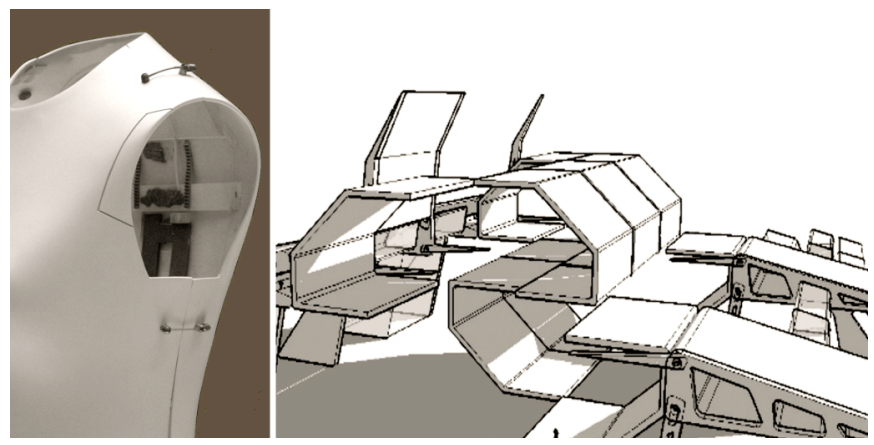

Figure 3: Remote Controlled Shell and Hinges

Left: Detail of Hussein Chalayan, Remote Control Dress (Image by author, Exhibition Wolfsburg, 2005)

Right: N Patankar, Prosthetic Surface Studio

The 'Remote Control Dress' (Husseyin Chalayan, Before Minus Now, 2000) suggests the Design Model of a remote controlled shell, supplemented and organized through hinges. (Fig 3) Based on industrial technology, modularization and standardization, the prefabricated form transports abstract notions of speed, dislocation and otherness. Chalayan investigated the basic idea and its techniques in a series of dresses with slight variations.

Made in composite materials of glass fiber sheets and resin, the dress is cast in a preformed, specially designed mould (Evans 270). The composite layers equip the shell with a resistance and depth; their surface is a three-dimensional material entity (Bettum 73-74), with diverse strata, light transmission effects, and modulated zones.

The cutting scheme is an idealized shape that incorporates diverse component parts. It follows the 'mechanics of form' (Wilcox 4) with a rigid smooth shell that echoes naval or automobile aerodynamics. Once this surface is cut, hinges, gears and wheels shift the fragments into formation, rendering its component parts ready for maneuver.

Chalayan uses a heterogeneous system of different materials, in which a composite skin responds via mechanical elements to a remote control order. This connection to data streams equips the surface formation with performative capacities. It opens along engineered constructive lines, to reveal secondary textural layers, or discrete zones of the body. The remote control system also enables an immediate response to data networks (news and communication lines), ephemeral or invisible environments (electricity, radiation, temperature zones) and virtual worlds. Though the shell displays a set tectonic frame, it really operates in a territory (Steele "Radical" 53) through the integration of virtual information or simulation of alternate realities.

'Remote Control Dress' proposes not an ideal but a composite system, defined by intricate stable connections of previously disparate components (Lynn "Body" 139). Skin, mechanics and data establish an operative field that formulates connections along lines of intensities. It thus establishes integral roles for specific element conditions -configuring available and absent states equally.

The Design Model of a remote controlled shell frames techniques of industrial design such as automobile, aeroplane and boat building, suggesting a production transfer. It is in fact already a classic of adaptable, flexible, modular or mobile design systems, that produce precise yet limited change conditions, and predominantly dislocate the object. But altered by informational data streams, it enters a territory independent or not transferable to material conditions. These data might even be processed onto the surface instead of merely controlling the mechanics of the form. Then, the prosthetic surface becomes a screen, a door to an alternate reality, and another passage in a global world. Yet another application might address a shift in scale in technique - the fabrication of an aeroplane hangar (Fig 3) generated by the same principles becomes than a territory in itself, and requires substantially different methods than the mere production and assembling of a singular plane. 


\subsection{Design Model 3: Prosthetic Insertions}

A crossover between elastic interval and independent forms is the Design Model of the prosthetic insertion that made a singular appearance with Comme des Garcons. 'Dress Becomes Body' (Rei Kawakubo, Spring-Summer, 1997), termed 'Lumps' Collection, is a series of synthetic gingham dresses with stretching performance.

The key strategy of this Design Model is an abstract distortion of pattern (Quinn 144), or deviation from anatomical form (Haye "Radical" 32). Padded insertions run asymmetrically over torso or shoulder, protrude from rear or bust (Evans 268). These 'Lumps' are an addition or expansion of specific areas (material inversion), a deformation of the overall body shape and experience (habitual-perceptual inversion), and an inversion of system inherent logic: 'on her dress she wears a body' (Haye 32). Kawakubo confronts perceived individual contours with extended perimeters, thus initiating a 'reciprocal transactions between body and space' (Sinclair 432).

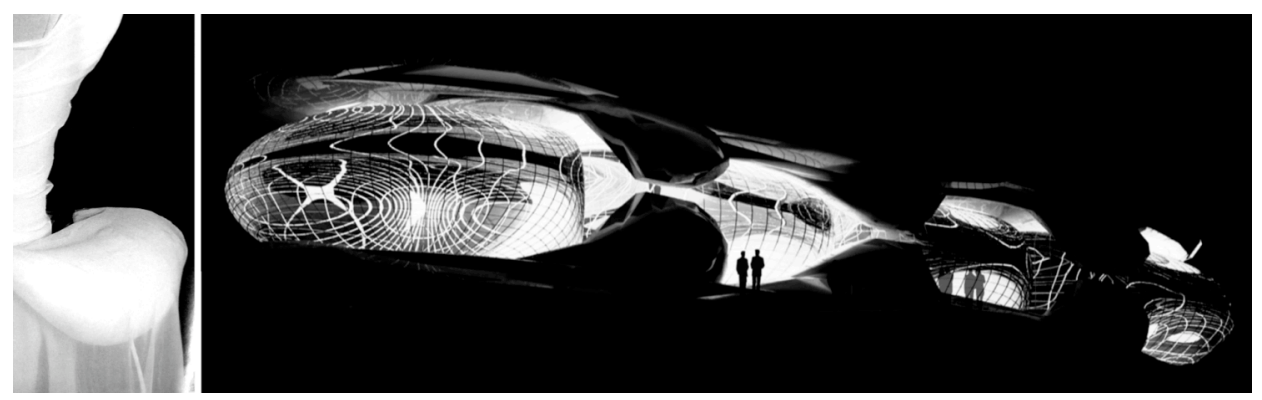

Figure 4: Insertions and Operative Field

Left: Detail of Comme des Garcons, Rei Kawakubo, “Lumps.” (Grand, France. Comme des Garcons. London: Thames and Hudson, 1998)

Right: H Chen, Prosthetic Surface Studio

Insertions vary from independent programmatic to inherent structural solutions, and enter the fabrication process at different phases (Fig 4). While clearly distinguishable in a semitransparent elastic fabric as interruptions of a close-fitting cutting scheme, in a different dress version they remain disguised in a checkerboard gingham fabric. The first suggests an unaltered cutting scheme in which an elastic fabric moves back into original position when temporal insertions are dislodged. The constructive line changes in contour due to the stretch capacities of the fabric. The operative field results from reversible alterations of the pads in form, size, location and duration. The second cutting scheme integrates a calculated permanent infill; it produces stable oversized body zones. Once the insertion is taken out, the structural deformation frames an absence; it defines a range of reference for spatial and programmatic alternatives without interfering with the exterior shape after construction.

This Design Model is characterized by a 'lumping technique', in which an 'operational field of potential interventions' is organized through a recombinative logic and thus provides 'ranges of different programmatic protocols' (Kolatan 79). It produces a programmatic topography in a range of conditions between nodal points set by a constructive reference line. While the exterior shape is unaltered, an inbuilt structural reservoir may provide unoccupied zones that can record later insertions. Or the interior structure defined a prosthetic surface formation in which movable layers of different size; height and atmosphere divide spatial sections along control lines.

\section{Conclusion}

The structure of change in architectural design can be informed by strategies of surface formations in the fashion realm. The paper has discussed a transfer from fashion to architecture that delivers principles and techniques to be exchanged between both realms. Reworked in operative and behavioral Design Models that deliver structural, material and detailed solutions, a new spatial semiotic can be framed.

The characteristics of surface formations in each Design Model produces a dynamic architecture that is singular and specific through rearrangement or appropriation of component parts or zones, through the impact of a user. This interaction between architecture and occupant is unique because it is simultaneous, post-productional and unfinished. As Sidlauskas remarks, 
'the wearer demands maximum adaptability, acknowledging, indeed affirming the provisional nature of human inhabitation, whether concrete or cloth' (Sidlauskas 261). Then, the provisional becomes a virtue, and the nature of change receives a quality that is not precisely controlled, but intuitive and emergent.

Change effects on form, techniques of material and structural conditioning, and underlying principles and generative Design Models have been a major focus of the paper. Yet a close surveillance of Miyake's approach to work ethics suggests that a fabrication of the raw material is at the core of techniques and thus of the creative design process: 'I start with making the fabric - we work from the yarn, we find, we invent.' The architect is then not a generator of form manifestations but of material, material use and production that are of equal importance. There is no sense to shape without the matter it is made of.

Each technology delivers its own application. In a system of invention and investigation, analogue fabrication machinery and computational programming, or techniques of conversion can be misused in order to submit new knowledge and applications, to deliver new results. Each explorative approach, manipulation, transfer frames an experiment and partial solution in material and structural matter. In the same manner, a transfer between principles of related fields or shared software programs and their applications might open new possibilities.

Kawakubo insists that 'creation is not something that can be calculated' (Grand 11) - yet new architectural solutions can be found, extended, and processed through techniques and transfer.

\section{References}

Auge, Mark. Non-Places - Introduction to an Anthropology of Supermodernity. London New York: Verso, 1995.

Benjamin, Andrew. "Surface Effects: Borromini, Semper, Loos." Journal of Architecture 11 (1) (2006).

Bettum, Johan. "Skin Deep." Contemporary Techniques in Architecture. Architectural Design AD 72. London: Wiley Academy, 2002: 72-76.

Evans, Carolin. Fashion at the Edge: Spectacle, Modernity and Deathliness. New Haven \& London: Yale University Press, 2003.

Evans, Carolin. Hussein Chalayan. Groningen: NAl Publishers, 2006. Essays by Caroline Evans, Suzy Menkes, Ted Polhemus, Bradley Quinn

Grand, France. Comme des Garcons. London: Thames and Hudson, 1998.

Grosz, Elizabeth. "The Future Of Space." Architecture From The Outside. Cambridge, Massachussets: MIT Writing Architecture Series, 2001.

Hiramitsu, Chikaku. "Japanese Tradition in Issey Miyake." Designhistoryforum 01 (2006). $<$ http://www.designhistoryforum.org/designdiscourse/ discourse/backnumber/papers/vol01/no1/01 135 43.pdf>.

Hodge, Brooke and Mears, Patricia and Sidlauskas, Susan. Skin+Bones: Parallel Practices in Fashion and Architecture. Los Angeles: Museum of Contemporary Art, and New York, London: Thames and Hudson, 2007.

Kolatan, Sulan and McDonald, Bill. "Lumping". Contemporary Techniques in Architecture. Architectural Design AD 72. London: Wiley Academy, 2002.

Leong, Roger. "The Zen And The Zany: Contemporary Japanese Fashion." Visasia (2003). access:

22.11.2005, <http://www.visasia.com.au/programmes/arts of asia/arts of japan 2003/the zen and the zany contemporary japanese fashion>.

Lynn, Greg. "Body Matters." Folds, Bodies And Blobs - Collected Essays. Bruxelles: Books-byArchitects, 1998.

Lynn, Greg. Animate Form. New York: Princeton Architetcural Press, 1999.

McCarty, Cara and McQuaid, Matilda. Structure and Surface - Contemporary Japanese Textiles. New York: Museum of Modern Art, 1998.

Miyake, Issey and Fujiwara, Dai. A-POC Making. Weil am Rhein: Vitra Design Museum, 2001. Includes essays by Dai Fujiwara, Mateo Kries, Issey Miyake. 
Miyake, Issey and Penn, Irving. Irving Penn Regards The Work Of Issey Miyake - Photographs 1975-1998. Boston, New York, London: Bulfinch Press.

Rahim, Ali, ed. "Bound Inspiration for Architectural Innovation." Contemporary Techniques in Architecture. Architectural Design AD 72. London: Wiley Academy, 2002.

Reinhardt, Dagmar. "Surface Strategies And Constructive Line - Preferential Planes, Contour, Phenomenal Body In The Work Of Bacon, Chalayan, Kawakubo." Colloquy 9. Monash

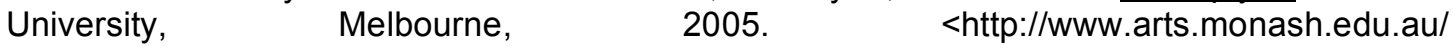
others/colloquy/issue9/reinhardt.pdf>.

Sato, Kazuko. "Issey Miyake Making Things: Clothes Beyond The Reach Of Time." Issey Miyake - Making Things. Zurich, Berlin, New York: Fondation Cartier Pou L'art Contemporain and Scalo, 1999: 18-66.

Simon, Joan. "Miyake Modern - Japanese Designer Issey Miyake - Interview." Art in America (Feb access: 22.11.2005, <http://www.findarticles.com/p/articles/mi m1248/is 2 87/ai 53868147>.

Wilcox, Claire. Radical Fashion. London: V \& A Publications, 2001.

Quinn, Bradley. Techno Fashion. Oxford New York: Berg, 2002. 